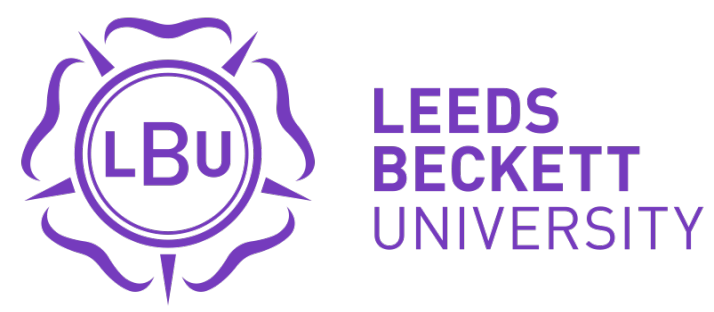

Citation:

Pierce, S and Gould, D and Cowburn, IHJ and Driska, A (2016) Understanding the process of psychological development in youth athletes attending an intensive wrestling camp. Qualitative Research in Sport, Exercise and Health, 8 (4). pp. 332-351. ISSN 2159-676X DOI: https://doi.org/10.1080/2159676X.2016.1176067

Link to Leeds Beckett Repository record:

https://eprints.leedsbeckett.ac.uk/id/eprint/3331/

Document Version:

Article (Accepted Version)

The aim of the Leeds Beckett Repository is to provide open access to our research, as required by funder policies and permitted by publishers and copyright law.

The Leeds Beckett repository holds a wide range of publications, each of which has been checked for copyright and the relevant embargo period has been applied by the Research Services team.

We operate on a standard take-down policy. If you are the author or publisher of an output and you would like it removed from the repository, please contact us and we will investigate on a case-by-case basis.

Each thesis in the repository has been cleared where necessary by the author for third party copyright. If you would like a thesis to be removed from the repository or believe there is an issue with copyright, please contact us on openaccess@leedsbeckett.ac.uk and we will investigate on a case-by-case basis. 
1 Accepted Manuscript: Qualitative Research in Sport, Exercise and Health.

2

3

4

5

6

7

8

9

10

11

12

13

14

15

16

17

18

19

20

21

22

23 Manuscript accepted and published online: 19 April, 2016

Michigan State University

2

3

4
intensive wrestling camp
Scott Pierce, Daniel Gould, Ian Cowburn, and Andrew Driska intensive wrestling camp
Scott Pierce, Daniel Gould, Ian Cowburn, and Andrew Driska

Institute for the Study of Youth Sports

\title{
Understanding the process of psychological development in youth athletes attending an
}

\author{
Institute for the Study of Youth Sports
}




\section{Abstract}

2 This study used a grounded theory methodology to understand if and how psychological

3 development in youth athletes was facilitated by an 'intensive' summer wrestling camp

4 experience. The theoretical sampling approach involved 10 athlete participants of the camp, nine

5 parents of athletes, the director of the camp, and four camp staff members, who took part in a

6 series of interviews before, during, and after the camp. Two researchers were also embedded in

7 the camp and attended all sessions, took detailed notes, collected camp materials, and conducted

8 observations. Following Corbin and Strauss' (2008) analysis approach, a model is presented that

9 outlines how youth participants' developed psychological qualities from the coach-created

10 challenges and adversity that were systematically designed to facilitate sport performance

11 enhancement and life skills. Variations emerged in psychological antecedents and characteristics,

12 how the challenging wrestling camp environment was interpreted and experienced, and how

13 learning was transferred to sport and life domains outside of the wrestling camp. This study

14 provided insight into a unique youth sport context that was able to simultaneously develop

15 psychological qualities to be used as sport performance enhancement and life skills.

17 Key words: Psychological skills, life skills, youth development 
Understanding the Process of Psychological Development in Young Athletes Attending an Intensive Wrestling Camp

Researchers in sport psychology (e.g., Bell, Hardy, \& Beattie, 2013; Holland, Woodcock, Cumming \& Duda, 2010) have shown a growing interest in understanding the role youth sport plays in facilitating psychological growth for performance enhancement and athletic talent development. Simultaneously, researchers in sport-based youth development (e.g. Flett, Gould, Griffes, \& Lauer, 2012; Larson, Hansen, \& Moneta, 2006), have been studying the role youth sport can play in fostering psychological growth for positive youth development (PYD). While these areas of research have much in common, the intersections about how psychological development occurs between them have largely been ignored.

In the sport-based talent development literature, psychological qualities have been described in many ways, and can be encompassed by the term, Psychological Characteristics of Developing Excellence (PCDEs). PCDEs are "not just mental skills such as imagery or goal setting but also include the attitudes, emotions, and desires young athletes need to successfully realize their potential" (MacNamara, Button, Collins, 2010a, p. 70). In the positive youth development (PYD) literature, life skills have been defined as "those internal personal assets, characteristics and skills such as goal setting, emotional control, self-esteem, and hard work ethic that can be facilitated or developed in sport and transferred for use in non-sport settings" (Gould \& Carson, 2008, p. 60). While a range of terms (ie., assets, skills, characteristics, attitudes, emotions, and desires), have been used across the two lines of research, both seek to understand and describe the key psychological qualities an athlete possesses or can develop in sport. The two research domains are different, however, with one focusing on application in sport and one on application in other life contexts. The defining factor that separates the two areas of study is 
1 the concept of transfer. In particular, for a psychological quality to be a life skill, it must be

2 transferred from one domain (i.e., sport) to another life domain (Gould \& Carson, 2008). The majority of athlete talent development research that explores psychological qualities

4 has focused on adults, with less attention focused on how these qualities are developed in young

5 athletes. It has been found that a number of personal dispositions (e.g. adaptive perfectionism,

6 optimism), psychological attributes (e.g. confidence, emotional control), and cognitive-

7 behavioral strategies (e.g. performance routines, self-talk) have been linked to athletes who have

8 succeeded at the elite or Olympic level (Gould \& Maynard, 2009). Having established that

9 development is a long-term complex process involving a talented individual and a strong support system (Gould, Dieffenbach, \& Moffett; 2002), researchers have turned their attention to

11 understand how and under what conditions psychological qualities develop.

One study that has looked at the psychological development of elite young athletes was

13 conducted by Holland and colleagues (2010). Examining young elite rugby players, they found

14 that youth use performance strategies (e.g., self-talk, visualization), team-based strategies (e.g.,

15 role clarification), strong support systems, and reflection on action to help the development of

16 psychological qualities. However, the dynamic process is individualized, where athletes learn

17 and utilize different PCDE's at various stages of development, depending on their ability to self-

18 regulate their progress and manage the stressors and challenges they are faced with (MacNamara, 19 Button, \& Collins, 2010b).

Coping with stress has been a salient theme across studies of elite athletes, thus, recent

21 research has focused on the development of psychological qualities used to cope with stress and

22 challenging experiences in athlete development (Connaughton, Hanton, \& Jones, 2010; Fletcher

$23 \&$ Sarkar, 2012). These investigators have noted the value of manipulating athlete environments 
1 to create adverse experiences that facilitate the learning of mental toughness, resilience, and

2 coping skills (Bell, Hardy, \& Beattie, 2013; Collins \& MacNamara, 2012). Bell and colleagues

3 (2013), for example, designed a mental toughness intervention training program for cricketers

4 (aged 16 to 18) that systematically introduced punishment-conditioned stimuli (e.g., exclusion

5 from training if not punctual) and transformational leadership training for the athletes. Cricketers

6 in the intervention group showed higher improvements in mental toughness and performance in

7 competitive situations than the control group. Not only did these findings provide support for the

8 use of systematic mental toughness training for athlete talent development, but highlighted the

9 need to understand how programmatic features, such as effectively designed punishment, can

10 influence athlete development (Bell et al., 2013).

11 Meanwhile, researchers in sport psychology have also explored psychological qualities in

12 young athletes through the lens of PYD, and have shown that sport participation for young

13 people can contribute to the growth of qualities such as initiative, teamwork, control of emotions, 14 and empathy (e.g., Gano-Overway, Newton, Magyar, Fry, Kim, \& Guivernau, 2009; Larson et

15 al., 2006). Much attention has centered on how programs can be designed and structured to

16 influence development. Petitpas, Cornelius, Van Raalte, and Jones, (2005) stated that

17 developmental youth sport programs should include caring mentors, have a focus on specific

18 assets or skills for sport and life situations, and be structured in an appropriate context.

19 Furthermore, the motivational climate (MacDonald, Côté, Eys, \& Deakin, 2011), specific

20 teaching strategies (Gould, Collins, Lauer, \& Chung, 2007), and the quality of the coach-athlete

21 relationship (Gould \& Carson, 2010) can influence PYD and life skill development.

22 Consequently, evaluations of life skill-focused youth sport programs, such as The First Tee golf 
1 program, have produced promising findings to show that life skills can be developed in a

2 systematically designed sport program and transferred to other life domains (Weiss et al., 2013). While talent-focused and life skills-focused sport programs are conceptually different in

4 their intended outcome, the conditions, techniques and processes (i.e., focus on developing

5 specific qualities or assets, coach-athlete relationships, support systems, motivational climate)

6 identified for developing psychological qualities across the two areas are similar. To this point,

7 Gould, Griffes, and Carson (2013) have contended that the mental toughness skills have the

8 potential to be life skills as they are attributes developed in sport and can be used in other areas

9 of life. Further, Turnnidge and colleagues (2014) have recently posited that psychological

10 qualities can become life skills as the result of both explicit approaches and implicit approaches.

11 Most notably, the implicit approach implies that some programs focus on teaching psychosocial

12 qualities for participants to use primarily in the sport setting, and no intentional strategies for

13 transfer are needed because participants naturally transfer these qualities to other areas of life on 14 their own.

The need has therefore arisen to question how youth sport programs can contribute to the

16 development of psychological qualities to use both for enhancing sport performance and as life

17 skills. This is especially relevant from a scientific perspective because: (1) there is a growing

18 need to examine how sport programs and talent development education function to impact on

19 psychological growth of young athletes (Collins \& MacNamara, 2012); and, (2) the National

20 Research Council and Institute of Medicine's have called for researchers to examine the

21 processes and contextual factors that foster developmental outcomes in sport-based PYD

22 programs. (Eccles \& Gootman, 2002; Gano-Overway et al., 2009). 
This issue is also particularly relevant from a practical standpoint. At the youth sport

2 level, the vast majority of programs have multiple goals including both performance

3 enhancement and personal development of the athletes. Furthermore, summer sport camps are an

4 increasingly popular experience for young athletes and a growing industry, estimated to produce

$5 \$ 15$ billion in revenue annually in the United States (American Camping Association, 2013).

6 Several studies have examined the effects of summer sport and physical activity camps

7 specifically designed to enhance positive youth development (PYD) for underserved youth (e.g.,

8 Anderson-Butcher, Riley, Iachini, Wade-Mdivanian, Davis \& Amorose, 2013), yet, investigators

9 have not examined the 'competitive' sport camp experience that also places major importance on skills instruction for enhanced talent and youth development.

With this scientific understanding as a foundation, we as researchers, were provided with

12 a unique opportunity to study an intensive youth wrestling camp that has the explicit goal to

13 develop psychological qualities for wrestling and for life. The camp is designed and directed by a 14 well-respected coach and leader in the United States wrestling community, and anecdotally in

15 that community has the reputation of being successful in achieving its goals. The present study is 16 a component of a wider project designed to examine if and how an intensive wrestling camp has

17 long-term effects on the psychological development of the young athletes involved. In the first

18 manuscript of the project, quantitative findings showed that 70 young athletes reported

19 improvements occurring in goal setting/mental preparation, achievement motivation and

20 confidence, coping with adversity, peaking under pressure, concentration, freedom from worry,

21 as well as state hope scale constructs of agency and pathway, and trait sport confidence (Driska,

22 Gould, Pierce \& Cowburn, under review). The first study provided strong evidence that a

23 number of psychological changes were evident in the young wrestlers and persisted over time, 
1 yet did not explore the process of 'how' the camp functioned to stimulate the changes seen in the

2 participants. The purpose of this study was to utilize a grounded theory approach to provide an in

3 depth understanding of if and how psychological development in youth athletes was facilitated

4 by the camp experience.

5

\section{The Intensive Wrestling Camp context}

\section{Method}

Approval for this research project was gained from the university human research protection program prior to the study, and the camp director allowed the research team to use his name and the camp organization name in the presentation of the study findings.

The camp studied was a 14-day over-night camp J Robinson Intensive Wrestling Camp attended by high school wresters, aged 14-18. The structure for this camp involved a great deal of physical training and is loosely based on Army Ranger training model. A typical daily schedule included a one-hour morning workout, a two-hour wrestling technique session, a two-hour hard wrestling session, a one-hour evening workout, and a one-hour evening mental attitude session. Throughout the camp, strict hydration and hygiene regulations were in place to manage the health risks specifically associated with intense training for wrestling. Along with the goals of improving wrestling ability and performance, the camp advertised that it would develop seven key virtues: hard work, dedication, discipline, sacrifice, accountability, responsibility, and service (labeled the $J 7$ by the camp director). The camp staff taught mental skills such as goalsetting and goal-based imagery, shared personal examples of their own athletic and personal development, and guided athletes in the completion of individual reflective activities using a camp journal. To additionally reinforce desired behaviors, the camp employed an effort-based reward system and a points system to determine who graduates from the camp. Participants 
1 begin with 750 points, and need 525 points to graduate from the camp; camp graduates receive a

2 coveted I DID IT t-shirt as an award. All participants began camp with 750 points but lost points

3 for failing to follow camp rules or meet camp requirements.

4 Research approach

A grounded theory methodology was deemed appropriate for this study because there are

6 empirical and conceptual gaps (Corbin \& Strauss, 2008) in the sport psychology literature about

7 how youth athletes develop psychological qualities from youth sport experiences for sport and

8 life success (Gould \& Carson, 2008). Holt and Tamminen (2010) have advocated for the focus

9 on methodological coherence as a guiding principle in grounded theory research studies. For this

10 reason, a systematic process was followed to ensure congruence between philosophical

11 viewpoints, theoretical perspectives, and the research question/s of interest (Holt \& Tamminen,

12 2010; Mayan, 2009; Morse, 1999). Further, a thorough description of the nuanced grounded

13 theory approach is provided to present an ecologically valid representation of psychological

14 development through the youth sport camp (Hutchinson, Johnston, \& Breckon, 2013).

This study sought to understand youth athlete psychological development using an

16 interpretivist philosophical perspective. In particular, the goal was to understand the meanings,

17 purposes and interpretations that athletes and coaches gave to experiences, actions and

18 interactions with others at the wrestling camp, related to athlete psychological development

19 (Smith \& Obsorn, 2008). Because this perspective asserts that there are multiple co-existing

20 realities among individuals (Guba \& Lincoln, 1994), it was deemed appropriate that Corbin and

21 Strauss' (2008) variant of grounded theory guided the research process.

This study began without a pre-defined theoretical framework for youth athlete

23 psychological development (Corbin \& Strauss, 2008). However, knowledge from academic and 
1 technical literature was recognized about what psychological qualities might be taught for

2 athletic development (e.g., Gould \& Maynard, 2009), and for positive youth development (e.g.,

3 Benson \& Satio, 2000), and the influential role of the coach and support system (e.g., Gould \&

4 Carson, 2008). This existing knowledge was used to help guide the interview questions in the

5 initial theoretical sampling (Corbin \& Strauss, 2008; Tamminen \& Holt, 2012).

$6 \quad$ Sampling strategy

7 Grounded theory research involves a spiral of cycles of data collection, coding, analysis,

8 writing, design, theoretical categorization, and data collection (Bryant \& Charmaz, 2007).

9 Sampling procedures occurred over several phases, driven by the need for theoretical sampling,

10 and involved the collection data from places, people, and events that maximized the development

11 of concepts and theory (Corbin \& Strauss, 2008), and is described below and shown in Figure 1.

12 The initial sample was purposively selected based on the research question, to understand

13 if and how psychological development in youth athletes was facilitated by the camp experience.

14 The camp director was identified as necessary for the initial sample to gain insight into how the

15 camp was structured and designed to influence athlete psychological development. Additionally,

16 from 15 assenting youth at the camp, 10 were identified as a suitable initial sample. This sample

17 was selected to provide variation in age, camp experience and gender, and according to the camp

18 staff, provided a fair representation of the 210 camp attendees. The director participated in a

19 semi-structured interview to obtain his views of the broad youth athlete and contextual factors

20 that may influence psychological development at the camp (e.g., how does the camp influence

21 athlete development?), and semi-structured interviews were conducted with each of the 10

22 athlete participants in the first two days of the camp with the purpose identifying the broad 
1 personal and contextual factors that may influence psychological development at the camp (e.g.,

2 what are your personal goals for the camp?). Initial coding and analysis from the director and athlete interviews revealed concepts

4 related to the camp design (e.g., demanding camp schedule) and the director's philosophy for 5 athlete development (e.g., need to understand consequences to learn), as well as concepts related

6 to similarities and variations in the athletes' background, personal goals for the camp, changes in 7 confidence, engagement with coaches, identification of the challenging camp environment, and

8 perceived developmental outcomes. These concepts guided the theoretical sampling and

9 instigated continual mini-cycles of coach and athlete interviews and observations, coding and 10 analysis from interviews and observation memos, and subsequent coach and athlete interviews 11 and observations, throughout the two week camp. This helped to build an understanding of the 12 multiple interpretations of the psychological development of youth at the camp. The interviews 13 were conducted with the camp director to inquire about his interpretation of the emergent 14 concepts (e.g., how would you describe changes in athlete confidence over the camp?), and with 15 the athletes to gain their interpretation of these concepts identified in the open coding (e.g., you 16 have mentioned the tough camp schedule, how is that influencing you today?) (Corbin \& Strauss, 17 2008).

The iterative process of initial coding and memos identified the next phase of sampling, which logistically occurred simultaneously with the initial phase of sampling. Continued coding

20 during the camp revealed that coaches and the camp materials (e.g., journal, daily quotes) were

21 influential in providing behavioral feedback and reinforcement for the athletes to facilitate

22 psychological development. This phase of theoretical sampling involved interviews with four

23 coaches/trainers and the collection of all supplementary camp materials, to gain additional 
1 interpretations and insight about the emerging concepts that influenced athlete development (e.g.,

2 describe the feedback and reinforcement you provide athletes and why you use this approach?). Immediately following the camp, coding continued and early theoretical categories and

4 descriptions guided the need for a subsequent phase of sampling. Specifically, psychological

5 development was an identified as an on-going process influenced by athlete reflection and

6 contextual factors outside of the camp. Focused on these emergent concepts, this phase of

7 theoretical sampling involved eight youth athletes, who completed interviews in the week

8 following the camp (e.g., you described changes in confidence during the camp, how would you

9 describe your confidence now?). Two athletes chose not to participate in these interviews.

11 understanding of life skill development and transfer (e.g., Gould \& Carson, 2008), revealed that

12 the camp was attempting to teach life skills, and that time, athlete post-camp experiences and

13 contextual factors outside of the camp would influence whether psychological development was

14 maintained and skills were transferred to other life domains. For this reason, the next phase of

15 sampling involved interviews with the same eight athletes approximately nine months following

16 the camp that focused on the emergent concepts and theoretical development (e.g., describe your

17 memories of the daily camp lectures and if you believe the talks have influenced your life outside 18 of the camp).

Following the athlete interviews, a core category was identified, along with a working 20 grounded theory, to best explain how psychological development occurred for the athletes. To 21 refine the theoretical categories and gain multiple viewpoints to build the emergent process, the 22 next phase of sampling involved interviews with parents of the youth athletes. Parents were 23 individuals with regular interactions with the youth participants and provided alternative 
1 interpretations the emergent concepts (e.g., change in confidence) and of development during

2 and after the camp (e.g., do you think the camp had an influence on your child outside of

3 wrestling? If so, how?). Finally, the seventh phase of sampling focused on confirming and

4 detailing the categories related to systematic approach and coaching approaches used at the

5 camp. The camp director was therefore involved in additional interviews approximately one year

6 following the camp.

$7 \quad$ Participants

8 In total, 24 participants volunteered to take part in interviews. The initial sample included 9 the camp director, a 65 year old male, who was in his $35^{\text {th }}$ year of leading the camp and 10 youth 10 camp participants (nine male and one female), aged between 14 and 17 years, who participated

11 in multiple interviews before, during and after the camp. To facilitate theoretical sampling, three

12 male camp coaches, one female athletic trainer, and nine camp participant parents (four mothers 13 and five fathers) participated in interviews during and after the camp.

14 Data collection

A flexible approach taken to the data collection process to facilitate and allow for the

16 interaction of collection and analysis of data (Holt \& Tamminen, 2010). Interviews,

17 observations, and document analysis were utilized as methods of data collection to maximize the 18 theoretical sampling.

19 Interviews.

Initial semi-structured interviews were conducted in person with each of the 10 athlete

21 participants in the first two days of the camp, with an average duration of 20 minutes.

22 Throughout the camp, a total of 38 semi-structured interviews were conducted in person during

23 the camp across the 10 participants (ranging between three and eight interviews per athlete), with 
1 an average duration of 11 minutes. In the two weeks following the camp, semi-structured phone

2 interviews were conducted with eight participants, with an average duration of 23 minutes.

3 Finally, nine months following the camp, a semi-structured phone interview was conducted with

4 the eight athletes with an average duration of 33 minutes. Prior to the camp, the director

5 participated in a semi-structured interview which was 77 minutes in duration. During the camp,

6 four semi-structured interviews were conducted with the camp director in person with an average

7 duration of 18 minutes. A semi-structured interview was conducted in person with the camp

8 director on the final day of the camp, which was 25 minutes in duration. Approximately one year

9 after the camp, the director participated in two in person semi-structured interviews, with a total

10 duration of 248 minutes. During the camp, semi-structured were conducted in person with three

11 camp coaches and one athletic trainer, with an average duration of 32 minutes. After the camp,

12 semi-structured, phone interviews were conducted with one or both parents of each athlete, with

13 an average duration 26 minutes.

14 Observations

Throughout the 14 day duration of the camp, two researchers were embedded in the camp

16 in order to observe the wrestling camp activities and the athlete participants. Observations were

17 made from a holistic viewpoint, generally attuned to the broader context of the camp. Attention

18 was also given to specific coaching actions and behavior, as well as participants and their

19 experiences and interactions in the context. The observations served to enhance the researchers

20 understanding of the camp context and athlete psychological development, which served as the

21 sensitizing concept, or key issue of interest (Patton, 2002). The two researchers participated in

22 regular informal reflective discussions and memo writing, which produced approximately 30

23 single spaced pages of detailed field notes related to objective observations and subjective 
1 reflections of the actions, behaviors, and interactions observed at the camp (Patton, 2002).

2 Throughout the camp, it was not possible for the researchers to transcribe each interview, thus,

3 the researcher discussions and memos from observations were critical in informing the open

4 coding and subsequent the theoretical sampling (Corbin \& Strauss, 2008).

5 Camp materials

$6 \quad$ Corbin and Strauss (1998) suggest that data collection should be flexible to assist the

7 development of theory. To understand how the camp influenced athlete psychological

8 development, the researchers accessed and obtained all of the information given to the young

9 athletes at the camp. This material included: a reflective journal that each athlete received which

10 included exercises to be completed by the athletes; the camp DVD that included similar material

11 to the journal; the thought of the day, quote of the day, story of the day, and cartoon of the day

12 that were presented to athletes in a poster in the common camp areas each day; and a historical

13 fiction novel that was promoted to the athletes as being important to read to facilitate

14 psychological growth.

15 Data analysis

16 Data analysis was initiated immediately following the initial sampling phase to ensure

17 that both data collection and analysis were integrated (Corbin \& Strauss, 2008), and to recognize

18 that insights and interpretations emerged to shape the understanding and perspectives of the

19 researchers. This process is integrated into Figure 1.

In the theoretical sampling phases during the camp, initial open coding was used to

21 identify any concept that was relevant to the process psychological development at the wrestling

22 camp (Corbin \& Strauss, 1998). These concepts were noted in researcher memos and guided the

23 questions used in subsequent in-camp interviews. Following the camp, all interviews were 
1 transcribed and observation notes were reviewed and refined. This allowed for further open

2 coding and the introduction of axial coding of interviews, observations and camp materials

3 which focused on developing the meaning and description of each concept and its relevance to

4 youth athlete psychological development. This iterative process allowed for the identification of

5 emergent categories, subcategories (Corbin \& Strauss, 1998), and indicated the need for post-

6 camp interviews with athletes. Axial coding continued following these interviews to help refine

7 categories and to begin theoretical development. This process included using constant

8 comparative analysis to identify possible relationships between concepts and categories (Bryant

$9 \&$ Sharmaz, 2007; Corbin \& Strauss, 2008). As such, these categories (e.g., outside distractions

10 removed), represented the multiple interpretations of the athletes, coaches, and researcher

11 observations, and were reduced into, and depicted by more conceptual terms about athlete

12 psychological development (e.g., immersive camp environment) (Corbin \& Strauss, 2008). The

13 theoretical formulations that emerged had general applicability to all the cases in a study, with

14 the specific categories and concepts providing the details that helped to bring out the differences

15 and variations in each case (Corbin \& Strauss, 2008). After the continued sampling, nine-months

16 following the camp, a core category emerged to encapsulate and explain the grounded theory as a

17 whole, and was further defined and explained by smaller concepts and categories (Birks \& Mills, 18 2010).

Idiographic profiles were created for each athlete immediately following the axial coding

20 and initial theoretical development to help to gain a complete and holistic understanding of each

21 individual's unique experience. This was a four- to seven-page summary of each individual's

22 narrative (Gould, Udry, Tuffey, \& Loehr, 1996) of psychological development through and

23 following the camp experience. Each profile referenced the concepts and categories that emerged 
1 through the coding processes and helped to explain the developing theoretical model. Following

2 the completion of the idiographic profiles, parents and the camp director interviews provided

3 additional viewpoints and interpretations of athlete development. Coding of these interviews

4 helped to refine and describe categories and facilitated the use of diagramming the conceptual

5 relationships between the concepts in the emerging theory, and outline the process of

6 psychological development (Corbin \& Strauss, 2008). This process included constant review and

7 discussion between researchers on the analysis to identify the relationships between concepts,

8 provide depth in the categories, determine the fit between the data in each individual case, and

9 ultimately, identify how categories were interrelated into a larger theoretical scheme (Corbin \&

10 Strauss, 2008). Theoretical saturation was determined as respondents did not provide new

11 findings that differed from those given by previous respondents, and provided a thorough

12 depiction of the process of psychological development for young athletes from the camp.

Prior to the study, a review of literature was conducted to understand what was known in

14 sport psychology and youth development, related to the process of developing psychological

15 qualities in young people. Through the analysis process in this study, concepts emerged that were

16 not identified in the existing literature. For this reason, a delayed literature review was conducted

17 to explore the relevance of important concepts and their connection to psychological

18 development in youth sport. This was conducted to ensure that concepts and terminology used in

19 this study, matched that from existing research (Corbin \& Strauss, 2008; Tamminen \& Holt,

20 2012). For example, research and terminology was examined that related to stress-inoculation

21 training in general psychology, and learning transfer in educational and cognitive psychology.

22 This provided a necessary connection to facilitate theoretical integration and outline the process

23 of how psychological development occurred from the wrestling camp (Corbin \& Strauss, 2008). 
Finally, the diagrammed model that emerged from the analysis process was presented to a group of researchers and practitioners in sport psychology and youth sport. In addition, the camp director was sent a technical report that included the proposed model. This final step served as a means of peer debriefing, with researchers and practitioners asked to comment and critique the coherence of the model, relevant to the psychological development of youth athletes. The focus of this process was not on the accuracy of the model to the data, but rather on whether the model effectively explained how youth athletes may experience psychological development as a result of participating in the youth sport camp (Corbin \& Strauss, 2008).

\section{Results}

Multiple interpretations were captured to explain a process of youth athlete psychological development through the camp experience, and are presented in Figure 2 as an interrelated theoretical model (Corbin \& Strauss, 2008). The findings are explained by the core category that psychological development was facilitated by "coach-created challenges and adversity" that were systematically designed to facilitate psychological changes.

The model outlines key concepts and categories that explain the process of psychological development, and when taken together, shows similarities and variations in how individuals interpreted and experienced the process of psychological development through coach-created challenges and adversity in the camp. Psychological changes occurred as each individual athlete interacted with the camp environment, and then interacted with life outside of the camp environment. Individual psychological antecedents influenced the developmental experience of the camp participants. Athletes experienced psychological growth through the on-going, reciprocal development of self-confidence and a range of specific psychological qualities. This growth was facilitated by foundational pillars of the challenging camp learning environment. 
1 The three pillars included the immersive environment, strategic program design, and stress

2 inoculation based approach that guided the individuals' experiences. A systematic approach to

3 teaching and learning psychological skills was also identified to have an important influence on

4 what and how athletes' learned. Finally, learning transfer was identified in the immediate or

5 latent transfer of skills to sport-specific or life-general domains. What follows is a detailed

6 explanation of each factor influencing psychological development with evidence highlighting

7 athlete similarities and variations, and supporting its inclusion.

$8 \quad$ Individual psychological antecedents

9 Athlete psychological development was influenced by the individual's characteristics

10 entering into the camp, and their personal interpretation and expectations of the camp. Each

11 individual athlete had their own unique dispositions and orientations that influenced their

12 psychological development throughout and following the camp. It was found that all of the

13 participants entered the camp with a general awareness of the highly intense nature of the camp,

14 were nervous about the challenges ahead, yet, were motivated to participate in, and complete this

15 camp. Three common psychological antecedents emerged as important factors influencing one's

16 perception of the camp and the resultant psychosocial outcomes. These antecedents were an

17 individual's physical and psychological readiness, openness to learning about psychological

18 skills for wrestling and for life, and reflection on the meaning of the camp experiences and their

19 psychological development.

Collectively, the findings suggested that the more ready for, open to, and reflective about

21 psychological development an athlete was, the greater range and depth of growth in

22 psychological skills and characteristics as a result of the camp experience. For example, at the

23 beginning of the camp, one athlete indicated a readiness to learning by stating that the camp 
1 would help him gain 'a better understanding of what you want to do....try to get to know my

2 inner self, who I am' (Athlete 3). Other athletes were open to learning, with the focus that 'I'm

3 just trying to learn from everybody' (Athlete 2), or with an initial goal to 'get started on the

4 achievement process schedule' (Athlete 8). During the camp, these athletes actively sought

5 opportunities to reflect on their experiences and development, as noted in the following quote,

6 Right before its lights out, if I have a little bit of extra time, I walk around campus just to

7 clear my thoughts, get focused on what I wanna do. And in my diary I put things like,

$8 \quad$ like what I've been thinking (Athlete 8)

9 Conversely, some athletes entered the camp with few goals and little initial awareness

10 and reflection on the potential for psychological growth from the camp. For example, when

11 asked if he hoped to gain any mental skills from the camp, one athlete answered, "nah not

12 really...I already have a really good mental attitude' (Athlete 10). The researchers observed this

13 athlete to be inattentive during camp talks, late to attend practices, and unreliable in the

14 completion of journal activities early in the camp. This indicated an initial lack of openness to

15 learning from the camp activities, and this athlete took a longer time to identify and interpret

16 psychological growth from the camp.

17 The challenging camp learning environment

The camp learning environment was systematically designed by the camp director and

19 implemented with a focus on using coach-created challenges and adversity to facilitate

20 psychological changes. The immersive environment, strategic program design, and stress

21 inoculation-based approach emerged as the key foundations of the camp that explained the

22 adverse environment.

23 Immersive environment 
The camp director indicated that the camp environment was deliberately created and maintained so that the youth participants were immersed in the wrestling camp and forced to take responsibility for their own development. While youths were able to communicate via phone with family and friends outside of camp, specific restrictions were in place to eliminate outside distractions that were not focused on the development on the ' $\mathrm{J} 7$ ' set of psychological characteristics. The director stated that 'we deal with parents by not dealing with parents;' parents were not permitted to be present at camp throughout the 14 days. Further, participants were not permitted to leave the camp at any point. Additionally, the intensive camp schedule meant that youths had minimal time or energy to be participating in activities outside of the camp requirements. This immersive, closed environment removed outside distractions and demanded near total focus on wrestling and self-improvement. This was interpreted by athletes as a psychological challenge, but was recognized as something that assisted in focusing their attention on succeeding in the camp environment. 'I think it actually is worse you know, communicating with the outside world, cause then you just wanna go back [home] more...it feels like you're isolated...but I think anybody would go through that if they want to learn' (Athlete $3)$.

Strategic program design

The camp was purposefully and strategically designed for psychological development. The psychosocial goals of the camp were repeatedly addressed by the camp director and staff in the physical training sessions and in the mental attitude lecture sessions. These goals were also reinforced through events, activities, the camp journal, the thoughts, quotes, cartoons of the day, and rules the participants experienced at the camp. Psychological skills were constantly and intentionally being taught and reinforced by camp staff in this challenging environment, and this 
1 was understood by athletes. 'He puts everything on our own shoulders...like getting our journals

2 done, it feels like I have a lot more responsibility here' (Athlete 2). Youths were 'learning by

3 doing' (Camp director), through the continual programmatic challenges. The camp director

4 discussed the importance of 'laying in' specific messages at specific times to match the

5 experiential learning of psychological skills through the physical challenges, stating, 'you can

6 only give them certain talks at certain points in camp when they're dealing with the lessons that

7 you want them to learn because now they're receptive to it'. Additionally, he informed the

8 participants that he was 'giving them the answers to the test,' with the points system being based

9 on the premise that if a participant was to do everything right, follow the rules, and overcome the

10 structured challenges, he or she would graduate and develop the psychological qualities taught

11 by the camp.

While this strategic program design was interpreted by the camp director and coaches as

13 a critical program feature to facilitate psychological development, the athletes' were not initially

14 aware that the camp was designed to teach them skills for wrestling as well as life outside of

15 sport. At the beginning of the camp, one athlete's reason for attending the camp was to 'get

16 physically stronger, mentally stronger and become a better wrestlers, that's about it' (Athlete 2).

17 However, during the first week of camp, he stated that 'I definitely thought it would just be about

18 wrestling....less about life, but wrestling teaches you lessons about life, so it's all relevant.'

19 Other athletes took time to realize the purpose of the tasks and program structure during the

20 camp. In the first week, one athlete stated, 'filling out the journal entry part ...I don't know why

21 that's helpful,' but after the camp reflected, and stated 'I've actually started writing down a

22 checklist of what I want to finish everyday' (Athlete 7). While it took time, developing an

23 awareness of utility of the skills for sport and life helped the athletes believe in and use the skills. 


\section{Stress inoculation-based approach}

The camp director and camp staff discussed the process whereby the coaches strategically orchestrated and timed physical and psychological challenges to gradually increase the amount of stress placed on the participants over the two weeks. This was based on a stress inoculationbased model and the notion that exposing young athletes to milder forms of stress can bolster one's coping mechanisms (Meichenbaum, 2007). In overcoming the demands of the camp, the young athletes all identified that they physically worked harder during the camp than they had at any point in their lives, and this was viewed as an important factor contributing to psychological growth.

You can't describe how tough it is but it's like you have this level of hard work and then once you go to J Rob you realize how much harder that level can be...you think you're tough and then you go J Rob and you realize you're not as tough as you thought you were (Athlete 4).

A major theme reinforced in the camp was for each individual athlete to create a new definition of hard work for themselves. The achievement of working harder and harder and overcoming stress every day was interpreted by athletes as an important catalyst for their development of important psychological qualities to succeed at the camp. This was reinforced by one athlete who stated during the second week of the camp that,

I think they're trying to get people to quit, that's, and that's where you build the mental attitude... y'know, that's kinda what sets the camp apart, you have to work, like you can't just go through the motions... there's, like, the constant hours, there's no like, rest period, or days off or anything like that. You just have to keep going (Athlete 9) 
While the young wrestlers were asked to cope with increased amounts of stress, they were simultaneously provided educational about ways to cope with stress. Coaches were observed providing regular motivational and informational feedback and educational sessions on self-talk and visualization that was directly focused on overcoming stress. Systematic approach to teaching psychological skills

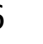

Alongside creating a challenging camp environment, the director and staffs' actions were guided by foundational beliefs about how the youth participants' best learn and adopt new behaviors. An intentional and systematic approach to teaching these qualities for sport and life emerged as a seven stage method for psychological change. Observations revealed that the key to the implementation of this approach was the repetition of the stages of change, the use of key words, the systematic integration of this message in the physical requirements of the camp, and the continual and varied connection of the messages to life relevant life situations.

To explain this process, the sixth day of the 14 day camp will be used as an example to outline how the psychological skill of goal setting was taught and reinforced. Throughout this day, the camp director reinforced the seven key factors or stages to psychological change (see Figure 3): (1) Individuals must understand that all behavior has consequences. He told the participants that 'goals are like a rudder in a boat, they steer your life, they allow you to decide what you want to do, they guide all aspects of your life'. (2) Individuals must take responsibility for their behavior. He emphasized that 'people don't plan to fail, they fail to plan.' (3) Individuals need to perceive that they are in control of their behavior and can change their behavior. He explained the goals he has personally achieved, such as climbing a mountain, and that he achieved the goals because he perceived that he was in control of achieving them. (4) Individuals need to make choice to change their behavior. He challenged the participants, stating 
1 that 'you either decide where you want to go or will you let the river of life take you anywhere?'

2 (5) Individuals must produce the change in their behavior. He gave them an assignment of

3 setting sport and life goals in their journals and ranking these goals in importance. (6) Individuals

4 need to continue this new behavior to create a new habit. He discussed how his own daily

5 schedule is driven by goals and urged the participants to set goals each day for the camp. (7)

6 Habitual change that will lead to positive behavioral consequences. He shared an example of a

7 former camper who became a Navy Seal because he learned how to set goals and made setting

8 goals a habit.

9 Rather than fully comprehending the cyclical teaching process during the camp, the athletes remembered key words and interpreted these messages as key skills that they needed to put into action every day to succeed at the camp and overcome the adversity. During the camp, one athlete emphatically stated, 'you've got to be real responsible, all the consequences fall on you, you hold yourself accountable...holding yourself accountable and responsible are the two biggest things I've learned' (Athlete 4). After the camp, one athlete recalled that, 'they [camp coaches] said life is a choice and if you want to get some things, you have to change so like change what you want to do for what you should do in order to get what you want' (Athlete 7). Another athlete talked about how he now planned to put these messages into action after the camp,

usually [I'd] just be like, 'well, you know, forget them, if they think I'm a bad kid,' but you know, the camp made me say, 'I wanna change their mind, I can change their mind (about people viewing me as a bad kid), I have the ability to change their mind... through my choices (Athlete 3)

Psychological development process of the camp. 
A range of psychological qualities were identified by participants as being developed through the camp experience (outlined in Driska et al., under review). The psychological qualities emerged in five categories: (a) enhanced confidence; (b) work ethic; (c) personal empowerment; (d) enhanced thought processes; (e) interpersonal skills. From a developmental perspective, a process of psychological growth emerged over time. Specifically, a reciprocal relationship emerged between the enhanced confidence and the development of the four categories of psychological qualities. For all athletes, an increase belief in one's ability to overcome structured adversity was seen to facilitate the development of psychological skills and characteristics. Subsequently, when the athletes' interpreted that they were developing and using specific psychological qualities to help overcome the adversity, they indicated an increasing sense of self-confidence as a wrestler and person. Temporal differences in increases in confidence were observed identified, with athletes who were physically and psychologically prepared for the camp challenges indicating an increase in confidence earlier in the camp. At the beginning of the camp, athletes' discussed self-doubt and a lack of confidence, '[I'm] constantly self-conscious, you know, you're not really tough enough for this...it really starts to get to your head' (Athlete 3). However, as the camp progressed, confidence grew. Athlete four stated, the first day, I was like tired, homesick and stuff, and now it's like 'getting through it, next workout's going to be okay'...the practices are definitely getting harder but it's easier to mentally prepare for them...I mean it's getting easier but uh, it's still hard (Athlete 2).

Athletes believed that the camp challenges were becoming easier and more manageable and in the second week, were observed to be more attentive, open to learning, and interactive with wrestlers and staff. This indicated an increased self-belief to complete the difficult tasks at the 
1

2

camp, and a sense he was developing the skills to help him prepare for and overcome the adversity that was placed upon him. This is highlighted by the group chant immediately after completing the camp, 'I did it, I did it, I did it - I'm going to be somebody!'

The work ethic and personal empowerment skills were the qualities most commonly identified by the athletes. All 10 athletes discussed learning these attributes from the direct teaching approaches and the use of them to work through the camp adversity. For example, goal setting was directly addressed in mental attitude lectures, journal exercises and coaching communication in physical training sessions. Goal setting was connected to the need to hold oneself accountable, as stated by one athlete nine months after the camp, that's another thing we were taught there, you know you're on your way, you set the direction for yourself, he [Camp Director] isn't there to help you along... you've got to hold yourself accountable for the goals you set, for the things you want to do (Athlete 4) The psychological qualities of enhanced self- and social-awareness, and interpersonal skills were also identified as being important attributes developed by the athletes. These skills were not as frequently mentioned by the athletes, and were not addressed as regularly or directly by the camp director, camp counselors or in the teaching curriculum. However, those athletes who entered the camp with goals of psychological development, who were reflective of their experience during and following the camp, and who were open to learning from the experience were more likely to indicate they learned awareness and interpersonal skills from navigating the challenges at the camp. For example, nine months following the camp, one athlete described the change he experienced in communicating with his mother, 
[I] was having a little miscommunication with my Mom...and we kinda, we sat down and we talked about it... and we came to a solution...before the camp we would have just been like, “ ehh...we gonna do what we wanna do.” (Athlete 8)

\section{Transfer of psychological skills for sport and for life}

The culmination of the process of psychological development was the transfer of the qualities to life outside of the camp as sport skills and life skills. Based on perceptions of athlete and their parents nine months following the camp, all athletes experienced learning transfer and it was interpreted as positive. This transfer was individualized based on individual interpretation and experiences outside of the camp, and emerged in dimensions based on timing (immediate and latent) and directionality (sport-specific and life general).

\section{Immediate sport-specific transfer}

Participants immediately transferred skills learned in the camp to their sporting endeavors outside of camp. Examples of immediate sport specific transfer include the direct transfer of the ability to be relaxed and calm in adverse situations during the camp to wrestling matches following the camp; the transfer of the foundational belief of hard work from the coach created challenges, and improving every day, as explained by one athlete, 'I've been trying to like get a little better each practice, like that $1 \%$ thing, like get $1 \%$ better every day' (Athlete 7 ), and the transfer of dedication and responsibility as guiding skills to embrace leadership roles in high school sport.

Immediate life-general transfer

Participants immediately transferred skills from the camp to life domains outside of sport. Hard work and personal empowerment psychological skills were described as skills reinforced by camp staff and structured within the camp, and transferred directly to life outside 
1 the camp. The following quote outlines one athlete's ability to immediately transfer his

2 prioritization and time management skills learned at the camp, directly to his school work and

3 studying, 'I've gotten more routine in my studying so I'm not as scattered out all over the place,

4 because that [routines] was one of the big things he was stressing to us the whole camp.' (Athlete $56)$

$6 \quad$ Latent sport-specific transfer

7 Latent or delayed transfer of skills from the camp to the sport context occurred when

8 athletes had an experience outside of the camp environment, related it to an experience inside,

9 and identified the need to utilize the psychological skill as a means to succeed in the sport

10 situation. For some participants, latent transfer occurred due to the participant going through a

11 difficult experience outside of the camp that they could relate to the challenges set in the camp.

12 For example, the transfer of persistence and dedication was experienced by two athletes who

13 incurred serious injuries in their high school wrestling season. These experiences caused

14 participants to reflect on the challenges at the camp, and utilize the skills of persistence and

15 dedication to help the recovery from the injuries. This is emphasized by the mother of one of the

16 injured athletes,

17 he was like, "you know mom if I can get through that [camp], I can get through anything." So he reflected back on the camp and you know being able to get through that. So getting through this knee thing [injury] is really a lot easier than going through that

\section{Latent life-general transfer}

Participants' also experienced the latent transfer of skills from the camp to various life

23 domains. Athletes who were self-reflective during and following the camp identified learning 
1 experiences that occurred during the camp and understood how the skills being taught could be

2 used in other areas of life. It took time and opportunities to use the skills before participants were

3 fully aware and confident that some skills were transferrable, as highlighted by one athlete

4 discussing time management as a life skill. my grades improved this year too, quite a bit and ah I just ah know that, like the time management part of the camp, it's something you don't really realize until afterwards and ah it just sort of taught me to manage when I can do my homework and when I can train for wrestling (Athlete 2)

\section{Discussion}

This study produced a grounded theory depiction of how youth athlete psychological development can be facilitated by systematically designed, coach-created challenges and adversity. In doing so, this study highlighted how the development of psychological qualities for performance enhancement and talent development, and for positive youth development can occur simultaneously. Furthermore, it underlined that youth athlete psychological development is an ongoing individualized process, and showed the value of studying athlete development from multiple viewpoints over a period of time.

\section{The growth of psychological qualities for talent and positive youth development.}

Through the physically and psychologically challenging wrestling experience, youth developed a range of psychological qualities that have been previously identified as being valuable psychological skills for performance enhancement and life skills for various life domains. Athletes identified the appraisal of stressful encounters as experiences of psychological growth (Fletcher \& Sarkar, 2012), and learned and utilize cognitive-behavioral strategies (e.g., visualization) to overcome the structured challenges (Gould \& Maynard, 2009; 
1 Holland et al., 2013). Further, athletes developed a sense of personal responsibility (Hellison,

2 2003), experienced individual success, developed confidence, and grew a sense of initiative

3 which prompted them to persist in the pursuit of achievement challenging goals (Larson, 2000).

4 Many of the recognized core mental toughness skills (e.g., dealing with adversity, confidence,

5 self-awareness) were developed as performance enhancement skills and life skills (Gould et al., 6 2012).

7 Addressing the need to understand how qualities were developed (Collins \& MacNamara,

8 2012; Eccles \& Gootman, 2002), the coach-created adverse environment emerged as being

9 critical in the development of psychological qualities for both talent development and life skill

10 development. Developmental opportunities were be created by providing participants with

11 relevant physical and psychological challenges with embedded, repetitive messages explaining

12 the importance of, and need to use taught psychological skills to overcome these challenges.

13 These findings provide support the conclusion of PYD researchers' Larson and Brown (2007),

14 who found that young people learn to deal with emotions from 'hot' emotional episodes and

15 drawing from the culture around them. Similarly, support is provided for the contentions of

16 researchers examining the psychological development of talented, elite athletes, such as Fletcher

17 and Sarkar (2012) and Bell et al., (2013) who suggested that experiential and structured stressful

18 encounters, and learning how to cope with those encounters, are valuable for psychological

19 growth. Further, Collins and MacNamara (2012) have referred the idea of building 'trauma' into

20 athlete development programs and the need to provide athletes with the skills and support to

21 overcome the challenges. This study provides a detailed of the coach-created adverse

22 environment in action, its effectiveness developing youth athletes, and shows that PYD doesn't

23 always need to be $100 \%$ positive. With planning and structure, psychological qualities can be 
1 simultaneously developed to enhance athletic talent and performance as well as be used in

2 multiple life domains.

Research in youth sports has shown that psychological skills can be developed for sport

4 and life through approaches of direct teaching (Gould et al., 2007), and experiential learning of

5 life skills (Jones \& Lavallee, 2009). In fact, Turnnidge and colleagues (2014) posited that

6 positive youth development occurs explicitly or implicitly through youth sport programming.

7 Few studies have, however, examined and provided a detailed and rigorous understanding of this

8 integration. The current study outlined a clear unification of the explicit and implicit processes

9 that influenced the development of transferrable psychological qualities in the youth athletes.

The grounded theory shows how the camp created a controlled environment for athlete

11 development and systematically employed both direct teaching and experientially learning of

12 psychological qualities, and adds depth to our understanding the processes and contextual factors

13 in youth sport that influence development (Eccles \& Gootman, 2002; Gano-Overway et al.,

14 2009). Direct teaching was seen through the repetitive definition, explanation and examples of

15 when and why to use the psychological qualities in the wrestling camp, and the use of examples

16 and colorful stories to explain how these skills connect to other life domains. Experiential

17 learning, or 'learning by doing' (Schön, 1987), was seen through the multitude of 'stress

18 inoculation' based activities and experiences (Meichenbaum, 2007) that reinforced the messages

19 shared in the direct teaching, such as the challenging physical experiences and specific, strict

20 camp rules and behavioral guidelines that required dedication and accountability. To expand on

21 Jones and Lavallee's (2009) promotion of experiential life skill development, the findings of this

22 study show that experiential learning was vital in encouraging the utilization of the messages

23 being directly taught and lectured, which ultimately served as reinforcement and repetition of 
1 explicit approaches to facilitate psychological development. Finally, the immersive closed camp

2 environment must be recognized as an optimal opportunity to foster the learning of

3 psychological qualities as it created an intense focus on athlete and personal development. A

4 youth sport camp offers a unique environment for the development of psychological skills and

5 characteristics. An organizer can control the majority of sport, social, and educational

6 experiences of the youth athletes, and limit outside influences and opinions, such as peers or

7 parents.

Finally, it must be recognized that the camp environment was systematically designed

9 and lead by an experienced, caring but tough director and coaching staff. Successful coaches, such as John Wooden (Gallimore \& Tharp, 2004), as well as respected youth American football

11 coaches (Gould et al., 2007), have been shown to have strategic approaches and rationales for

12 teaching psychological skills for sport and life. The camp design and use of adversity to

13 influence development was inextricably linked with the camp director's belief that young people

14 need to be challenged and need to learn a set of responsibility and dedication based skills to be

15 successful in sport and life.

\section{The individualistic process of psychological development and the transfer of life skills}

This methodological approach allowed for a range of young athlete developmental

18 journeys to be understood and provided a collective understanding of the individual

19 characteristics influencing psychological growth, how the individual experienced the sport

20 environment, and how he/she attempted to apply skills in other life domains (Corbin \& Strauss,

21 2008). Individual similarities and differences did, however, provide critical insight into the

22 process of psychological development, where ultimately, the learning and transfer of

23 psychological qualities resides in the learner (Berieter, 1995). The findings suggested that a 
1 youth athlete's openness to learning or a growth mindset, their psychological readiness, and their

2 ability to self-reflect influenced the way the camp was interpreted, the psychological qualities

3 that were developed through the camp, and the ability and tendency to transfer these skills to

4 sport or life outside of the camp. Some athletes thrived in this developmental context and were

5 able to maintain those changes over time, while others experienced change, but at a much less

6 impressive and maintainable level. These findings support literature focused on sport-based

7 psychological development that suggests reflection is important for the growth of resilience

8 (Fletcher \& Sarkar, 2012), and in the development of leadership skills (Martinek, Schilling, \&

9 Hellison, 2006). Further, it emphasizes that an individual's personal characteristics influence

10 their development of psychological skills in sport (Jones \& Lavallee, 2009), and their ability to

11 transfer of skills to different domains (Furman \& Sibthorp, 2013). This study provides evidence

12 to support the promotion of self-reflection, a growth mindset, and encourage physical and

13 psychological readiness as athletes enter a sporting context to help athletes learn psychological

14 qualities as sport skills and life skills. Further research on the psychological antecedents

15 simultaneously influencing athlete talent and youth development in sport is needed.

16 While research in sport has shown that many of life skills can be transferred (e.g. Jones \&

17 Lavellee, 2009; Holt, Tamminen, Tink, \& Black, 2009), the individuals' perspectives and

18 experiences of transferring life skills has received minimal attention. This study highlighted the

19 need to understand the learning of psychological qualities, and their subsequent transfer as life

20 skills, as one continual, intertwined developmental process. The transfer of life skills was

21 dependent on the specific psychological make-up of each individual athlete entering the camp,

22 their interpretation of their experiences in the sport camp, and their experiences outside of the

23 camp. For example, youth who were open to learning goal setting and discussed setting goals at 
1 the camp provided detailed examples of transferring the goal setting skill to school and other life

2 domains outside of camp. Additionally, some of the participants experienced critical incidents

3 outside of the camp, such as sporting injuries or changing schools, which were identified as

4 challenging or adverse experiences. This triggered the recollection and the coping skills learned

5 at the camp and elicited the latent transfer of coping skills to overcome the challenges. These

6 findings align with research on transfer in cognitive psychology which outlines an interactive

7 influence of the individual learner, the learning context (e.g., wrestling camp), and the transfer

8 contexts (e.g., academic classroom) (Burke \& Hutchins, 2007); as well as adventure-based

9 education research, that suggests that transfer is highly individualistic, difficult and complex

10 (Furman \& Sibthorp, 2013).

11 Furthermore, this study has helped to identify how youth athletes transferred life skills on

12 dimensions of similarity (sport-specific to life-general) and timing (immediate or latent). Similar

13 dimensions have been identified in learning transfer research across adult-based learning

14 disciplines, such as near transfer refers to transferring learning between very similar contexts

15 (e.g., learning in the camp transferred to high school wrestling) (Perkins \& Salomon, 1992)

16 versus far transfer refers to transferring learning to contexts that appear to be remote and

17 unfamiliar to one another (e.g., learning in the camp transferred to the classroom) (Perkins \&

18 Salomon, 1992). There are many unanswered questions related to the transfer of life skills from

19 sport. This study highlights a need to understand the individualistic ongoing process of sport

20 skills development and life skills transfer, and prompts further examination of the dimensions of

21 timing and directionality to expand our understanding of how and why psychological qualities

22 can be transferred from sport to other life domains.

\section{Implications for research and professional practice}


Youth athlete psychological development can be facilitated through systematically designed, coach-created challenges and adversity. However, this implication must be taken with caution. In many ways, the findings from this study support the approach that is often taken in Army Ranger 'special forces' type training where physically challenging tasks and environments are used to mentally train soldiers. This is not an approach that should be disseminated widely without knowing the coaches who will employ it and the context the coach is using. It takes a special coach with good emotional and contextual intelligence to use this approach, and it takes athletes who are willing to work through the challenges. In fact, Coach Robinson, the architect of this intensive camp, said in his interviews that it would be a mistake to use this approach with all youth. Participants must be motivated to improve and be at an appropriate physical and psychological development age to reap the benefits.

Youth sport programs can develop talent and life skills by integrating both explicit (e.g., lectures about responsibility) and implicit approaches (e.g., rules rewarding responsibility) to develop psychological qualities. This approach is not easy, however, it takes time and dedication to systematically structure a sport program, and the coach's philosophy and actions should align to maximize the opportunities for development. Finally, athletes interpret learning in a variety of ways and coaches must recognize that transfer is not guaranteed. From a research standpoint, we need to do more to study when, under what conditions and within whom such approaches might work, as individual differences were found in this study.

Like all studies, this project had limitations. First, each camp participant interpreted their experience differently. As only 10 athletes were involved in this study, this analysis may not provide a full range of experiences of all camp participants who participated in the camp. Approximately $10 \%$ of the participants dropped out of the camp being studied for various 
1 reasons, including one participant who was involved in the early phases of this study. His choice

2 not to continue participating in the study did not allow us to explore the long-term psychological

3 development of this 'drop-out' participant. Future research should seek to understand the sport-

4 based developmental experience of youth athletes who choose to drop-out or cease their

5 involvement in sport. Second, the camp was designed and implemented with the researchers

6 having no control. The specific timing and teaching of psychological skills was controlled by the

7 camp director and may be different in each different camp contexts with different youth

8 participants. For this reason, the camp was unable to be studied with the same controls that a

9 scientifically designed and evaluated intervention program would be. The grounded theory

10 approach effectively built an understanding of how this specific camp functioned and was

11 experienced, and future research should build on this approach with the use of specific program

12 evaluation theory and logic modeling to understand the detail the learning environments in

13 existing, non-intervention youth sport programs. Youth sport programmers and coaches should

14 also be encouraged to utilize program evaluation to understand how their programs are, and can

15 be, structured to facilitate psychological development. 
References

American Camping Association. 2013. ACA Facts and Trends. Retrieved from http://www.acacamps.org/media/aca-facts-trends

Anderson-Butcher, D., Riley, A., Iachini, A., Wade-Mdivanian, R., Davis, J., and Amorose, A. 2013. Exploring the impact of a summer sport-based youth development program. Evaluation and Program Planning. 37, 64-69.

Bell, J. L., Hardy, L., and Beattie, S. 2013. Enhancing mental toughness and performance under pressure in elite young cricketers: A 2-year longitudinal intervention. Sport, Exercise \& Performance Psychology, 2(4), 281-297.

Benson, P., and Saito, R. 2000. The scientific foundation of youth development. In N. Jaffe \& J. Marquis eds. Youth development: Issues, challenges and directions. Philadelphia, PA: Public/Private Ventures, 126-147.

Bereiter, C., 1995. A dispositional view of transfer. Teaching for transfer: Fostering generalization in learning, 2134.

Birks, M., and Mills, J. 2011. Grounded theory: A practical guide. Sage publications.

Bryant, A., and Charmaz, K. eds. 2007. The Sage handbook of grounded theory. Thousand Oaks, CA: Sage.

Burke, L. A., and Hutchins, H. M. 2007. Training transfer: An integrative literature review. Human Resource Development Review, 6(3), 263-296.

Camiré, M. 2014. Youth Development in North American High School Sport: Review and Recommendations. Quest, 66(4), 495-511.

Coakley, J. 2011. Youth sports: What counts as “positive development?” Journal of Sport \& Social Issues, 35, 306-324. 
1 Collins, D., \& MacNamara, A. 2012. The rocky road to the top: Why talent needs trauma. Sports Medicine, 42(11), 907-914.

Connaughton, D., Hanton, S., and Jones, G. 2010. The development and maintenance of mental toughness in the world's best performers. The Sport Psychologist, 24(2), 168-193.

Corbin, J., and Strauss, A. 2008. Basics of qualitative research: Techniques and procedures for developing grounded theory. Thousand Oaks, CA: Sage.

Driska, A., Gould, D., Pierce, S., and Cowburn, I. under review. A mixed-methods evaluation of mental skills acquisition and retention from a 2-week intensive wrestling camp. Manuscript submitted for publication.

Eccles, J. S., and Gootman, J. A. eds. 2002. Community programs to promote youth development. Washington, DC: National Academy Press.

Fletcher, D., and Sarkar, M. 2012. A grounded theory of psychological resilience in Olympic champions. Psychology of Sport and Exercise, 13(5), 669-678.

Flett, M. R., Gould, D., Griffes, K. R., and Lauer, L. 2012. The views of more versus less experienced coaches in underserved communities. International Journal of Coaching Science, 6(1), 3-26.

Furman, N., and Sibthorp, J. 2013. Leveraging experiential learning techniques for transfer. New Directions of Adult Continuing Education, 137, 17-26.

Gallimore, R., and Tharp, R. 2004. What a coach can teach a teacher, 1975-2004: Reflections and reanalysis of John Wooden's teaching practices. The Sport Psychologist, 18, 119-137.

Gano-Overway, L. A., Newton, M., Magyar, T. M., Fry, M. D., Kim, M.-S., and Guivernau, M. R. 2009. Influence of caring youth sport contexts on efficacy-related beliefs and social behaviors. Developmental Psychology, 45, 329-340. 
1 Gould, D., and Carson, S. 2008. Life skills development through sport: Current status and future directions. Sport \& Exercise Psychology Reviews, 1, 58-78.

3 Gould, D., and Carson, S. 2010. Coaching behaviors and developmental benefits of high school 4 sports participation. Hellenic Journal of Psychology, 7, 298-314.

5 Gould, D., Collins, K., Lauer, L., and Chung, Y. 2007. Coaching life skills through football: A 6 study of award winning high school coaches. Journal of Applied Sport Psychology, 19(1), $7 \quad 16-37$

8 Gould, D., Dieffenbach, K., and Moffett, A. 2002. Psychological characteristics and their 9 development in Olympic champions. Journal of Applied Sport Psychology, 14(3), 172204.

11 Gould, D., Griffes, K., and Carson, S. 2012. Mental toughness as a life skill. In Gucciardi, D., Gordon, S. eds. Mental toughness in sport: Developments in research and theory. London: Routledge, 163-186.

Gould, D., and Maynard, I. 2009. Psychological preparation for the Olympic Games. Journal of Sport Sciences, 27(13), 1393-1408.

16 Gould, D., Udry, E., Tuffey, S., and Loehr, J. 1996. Burnout in competitive junior tennis players: I. A quantitative psychological assessment. The Sport Psychologist, 10, 322-340. qualitative research, 2, 163-194.

Hellison, D. 2003. Teaching responsibility through physical activity. $2^{\text {nd }}$ ed. Champaign, IL. Human Kinetics. 
Holland, M.J., Woodcock, C., Cumming, J. and Duda, J.L., 2010. Mental qualities and employed mental techniques of young elite team sport athletes. Journal of Clinical Sport Psychology, 4, 19-38.

Holt, N. L., and Tamminen, K. A. 2010. Moving forward with grounded theory in sport and exercise psychology. Psychology of Sport and Exercise, 11(6), 419-422.

Holt, N., Tamminen, K. A., Tink, L., and Black, D. 2009. An interpretative analysis of life skills associated with sport participation. Qualitative Research in Sport \& Exercise, 1(2), 160175.

Hutchison, A.J., Johnston, L.H. and Breckon, J.D., 2013. A grounded theory of successful longterm physical activity behaviour change. Qualitative research in sport, exercise and health, 5(1), pp.109-126.

Jones, M. I., and Lavallee, D. 2009. Exploring perceived life skills development and participation in sport. Qualitative Research in Sport and Exercise, 1(1), 36-50.

Larson, R. W. 2000. Toward a psychology of positive youth development. American Psychologist, 55(1), 170.

Larson, R. W., and Brown, J. R. 2007. Emotional development in adolescence: What can be learned from a high school theater program. Child Development, 78(4), 1083-1099.

Larson, R. W., Hansen, D. M., and Moneta, G. 2006. Differing profiles of developmental experiences across types of organized youth activities. Developmental Psychology, 42(5), 849-863.

MacDonald, D. J., Côté, J., Eys, M., and Deakin, J. 2011. The role of enjoyment and motivational climate in relation to the personal development of team sport athletes. The Sport Psychologist, 25(1), 32. 
MacNamara, Á., Button, A. and Collins, D., 2010a. The role of psychological characteristics in facilitating the pathway to elite performance. Part 1: Identifying mental skills and behaviours. The Sport Psychologist, 24(1), 52-73.

MacNamara, Á., Button, A. and Collins, D., 2010b. The role of psychological characteristics in facilitating the pathway to elite performance. Part 2: Examining environmental and stagerelated differences in skills and behaviors. The Sport Psychologist, 24(1), 74-96.

Martinek, T, Schilling, T., and Hellison, D. 2003. Developing compassionate leadership in underserved youths. Journal of Physical Education, Recreation, \& Dance, 74, 33-39.

Mayan, M. J. 2009. Essentials of Qualitative Inquiry. Walnut Creek, CA: Left Coast Press

Meichanbaum, D. 2007. Stress Inoculation training: A preventative and treatment approach. In P. M. Lehrer, R. L. Woolfolk, and W. S. Sime. Principles and Practice of Stress Management, 3rd Ed. Guilford Press.

Morse, J. M. 1999. Qualitative generalizability. Qualitative Health Research, 9(1), 5-6.

Patton, M. Q. 2002. Qualitative research and evaluation methods. Thousand Oaks, CA: Sage.

Perkins, D. N., and Salomon, G. 1992. Transfer of learning. International encyclopedia of Education, $2^{\text {nd }}$ Ed. Oxford, England: Pergamon Press.

Petitpas, A. J., Cornelius, A. E., Van Raalte, J. L., and Jones, T. 2005. A framework for planning youth sport programs that foster psychosocial development. The Sport Psychologist, 19, 63-80.

Schön, D. 1987. Educating the reflective practitioner. San Francisco, CA: Jossey-Bass.

Smith, J. A., and Osborne, M. 2008. Interpretative Phenomenological Analysis in Smith, J.A. ed. Qualitative psychology: A practical guide to research methods. London: Sage Publications, 53-79. 
1 Strauss, A., and Corbin, J. 1998. Basics of qualitative research: Procedures and techniques for developing grounded theory. Thousand Oaks, CA: Sage.

3 Tamminen, K. A., and Holt, N, L. 2012. Adolescent athletes' learning about coping and the roles 4 of parents and coaches. Psychology of Sport \& Exercise, 13, 69-79.

5 Weiss, M.R., Stuntz, C.P., Bhalla, J.A., Bolter, N.D. and Price, M.S., 2013. 'More than a game': 6 impact of The First Tee life skills programme on positive youth development: project introduction and Year 1 findings. Qualitative research in sport, exercise and health, 5(2), 214-244. 
1

2

3

4

5

6

7

8

9

10

11

12

13

14

15

16

17

18

19

20

21

22 \begin{tabular}{|c|}
\hline Initial Sampling \\
\hline Pre-camp interviews with 10 athletes \\
Pre-camp interview with director
\end{tabular}

\begin{tabular}{|c|}
\hline \\
\hline Analysis \\
Initial open coding and memos identified concepts of interest
\end{tabular}

$$
\downarrow
$$

Sampling

Camp interviews with 10 athletes (38 interviews)

Camp interviews with director (five interviews)

Camp observations

\section{Analysis}

Open coding and memos identified concepts and need for multiple viewpoints

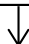

\begin{tabular}{|c|}
\hline Sampling \\
\hline Four coach/counselor interviews \\
Collection of camp documents \\
\hline
\end{tabular}

$$
\downarrow
$$

Analysis

Open \& axial coding, emergent categories and theoretical development

Sampling

Post-camp interviews with eight athletes

Analysis

Open \& axial coding, refined categories, theoretical development and early modeling

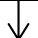

Sampling

Nine-month follow-up interviews with eight athlete

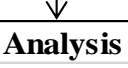

Open and axial coding, core category identification, continued modeling, and need for multiple viewpoints

17

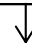

Sampling

Interviews with nine athlete parents

$$
\downarrow
$$

Analysis

Open \& axial coding, continued modeling, refinement of categories, and review of literature

\section{Sampling}

Two follow-up interviews with director

Analysis

Theoretical integration

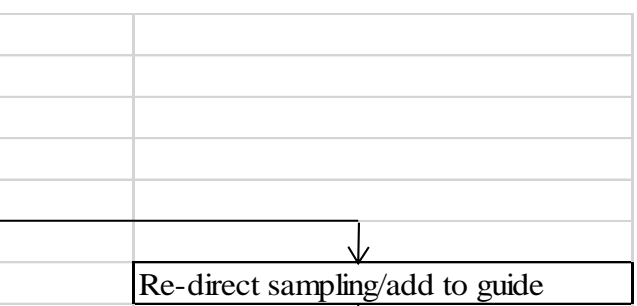

Re-direct sampling/add to guide
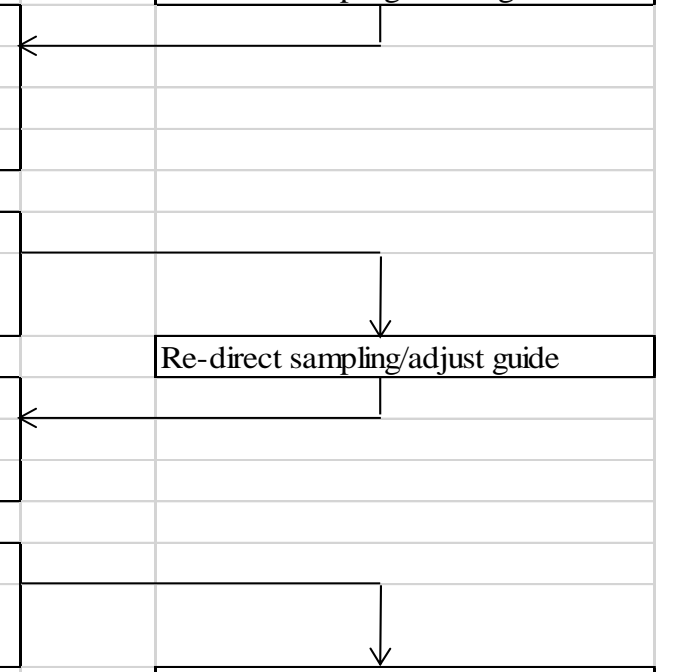

Re-direct sampling/adjust guide

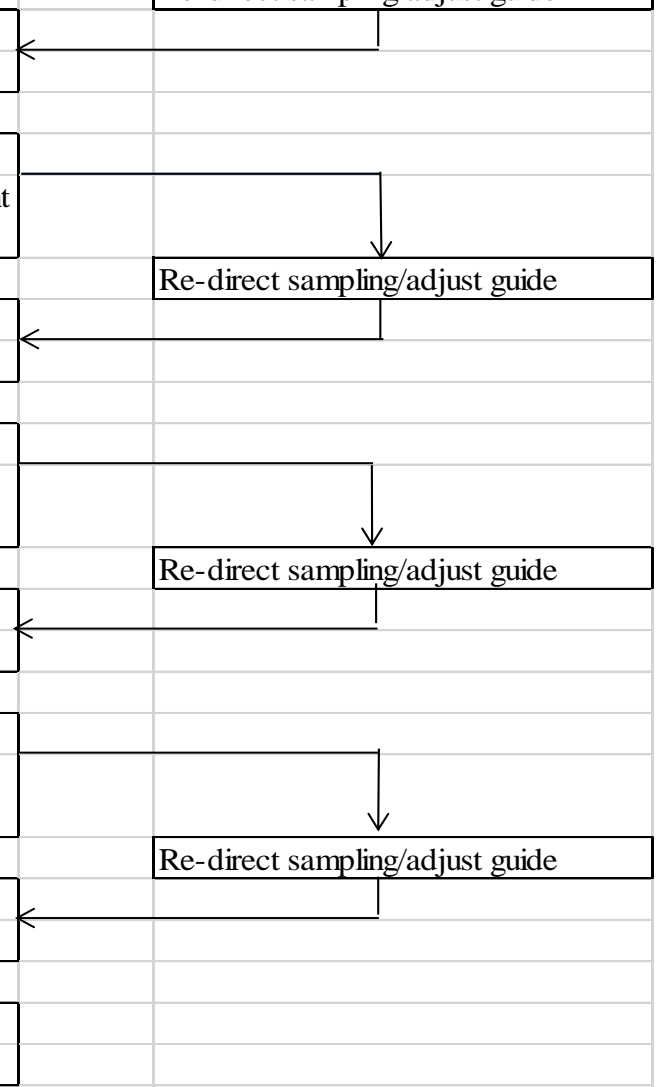

23 Figure 1. Theoretical sampling process 
6

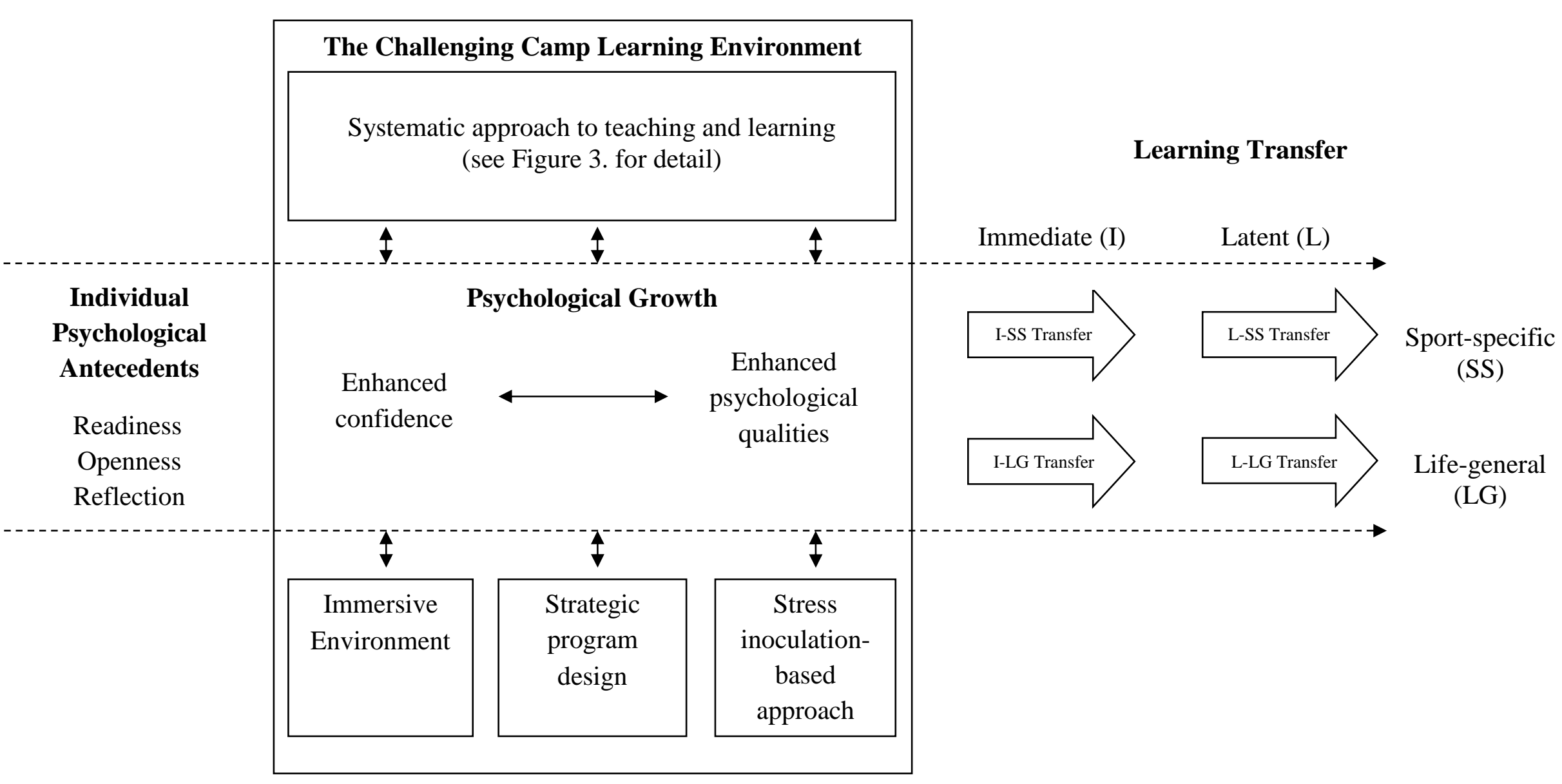


17 Figure 3. The systematic approach to teaching and learning psychological skills. 